\title{
Paradoxos do exercício de práticas de biopoder na Amazônia Paraense
}

\author{
Flávia Cristina Silveira Lemos, ${ }^{\star}$ Igor do Carmo Santos, Evelyn Tarcilda Almeida Ferreira, \\ Luzia Poça Sousa, André Benassuly Arruda \\ Universidade Federal do Pará, Belém, PA, Brasil
}

\begin{abstract}
Resumo
Este artigo visa pensar as relações de biopoder na Amazônia paraense, como elas operam deixando morrer, matando em nome da vida, confiscando terras, bens e corpos, ao atualizarem elementos da sociedade de soberania. Questionar este processo é um dos principais objetivos deste texto na medida em que traz um quadro dos acontecimentos da região amazônica paraense no campo dos extermínios de lideranças indígenas, ambientalistas e de tráfico de pessoas, trabalho análogo ao escravo, além, da exploração sexual e da intensa retirada de madeira e minérios, deixando a miséria, a destruição ambiental e os custos destes problemas para a população.
\end{abstract}

Palavras-chave: Amazônia; biopoder; Foucault; violação de direitos; Brasil.

\section{Paradoxes of practical exercise of biopower in the Paraense Amazon}

\begin{abstract}
This paper was thinking the biopower relations in the Amazon Pará, how they operate letting die, killing in the name of life, confiscating lands, goods and bodies, to update elements of society of sovereignty. Questioning this process is one of the main objectives of this text as it brings picture of the events of the Amazon region of Pará in the field of extermination of indigenous leaders, environmentalists and human trafficking and slave labor work, in addition, sexual exploitation and intense removal of timber and minerals, leaving poverty, environmental destruction and the costs of these problems for the population.
\end{abstract}

Keywords: Amazon; biopower; Foucault; rights violations; Brazil.

"Tanto amor perdido no mundo/ Verdadeira selva de enganos/ A visão cruel e desertal De um futuro de poucos anos/ Sangue verde derramado/ $O$ solo manchadol Feridas na selval A lei do machado/ Avalanche de desatinos/ Numa ambição desmedida/ Absurdos contra os destinos/ De tantas fontes de vida/ Quanta falta de juizo/ Tolices fatais/ Quem desmata, mata/ Não sabe o que fazl Como dormir e sonhar/ Quando a fumaça no ar/ Arde nos olhos de quem pode ver/ Terriveis sinais, de alerta, desperta/ Pra selva viver/ Amazônia, insônia do mundo/ Amazônia, insônia do mundo". (ROBERTO CARLOS; ERASMO CARLOS, 1989).

Essa é mais uma entre as várias vozes que cantam e clamam em favor desse território que traz consigo imensos paradoxos: a Amazônia paraense. Esta singela canção de Roberto Carlos nos chama a atenção para uma Amazônia que não consegue dormir, não consegue sonhar, devido às feridas provocadas pela "ambição desmedida", a "falta de juízo", as "tolices fatais" contra os "destinos de tantas fontes de vida".

No entanto, de qual Amazônia falamos? E que práticas poderíamos designar como de biopoder neste território e na gestão de sua população? Ora, não poderíamos cair na ingenuidade de achar que o perigo vem apenas de fora pela produção de um inimigo imperialista e

\footnotetext{
^Endereço para correspondência: Universidade Federal do Pará, Instituto de filosofia e ciências humanas. Rua Augusto Corrêa, 01 - Guamá. Belém, PA Brasil. CEP: 66075110.E-mail: flavazevedo@bol.com.br, igor_psico@yahoo. com.br, evyalmeida@gmail.com, luziapsousa@yahoo.com.br, arruda.belem@a gmail.com
}

colonizador? Não que esse objeto "inimigo de fora" não se materialize se pensamos nos interesses internacionais sobre a Amazônia, sobretudo, em termos de apropriação de seus minérios e recursos que compõem uma rica biodiversidade.

$\mathrm{O}$ artigo tem o objetivo de chamar a atenção para a multiplicidade de acontecimentos que ocorrem nesta Região e os efeitos desses na vida dos que lutam e tentam resistir à expropriação de recursos em moldes de coronelismo oligárquico local e regional e/ ou à gestão liberal da biodiversidade por grupos de interesses pertencentes ao Estado e aos empresários de multinacionais (GONÇALVES, 2010).

Assim, de certo modo busca-se analisar as composições de forças heterogêneas que arranjam e rearranjam a emergência do que é hoje a Amazônia paraense. Por isso, apesar de se evitar um discurso maniqueísta, pois se entende que não existe o "mau" ou o "bom" e sim, discursos políticos que forjam realidades, ganhando determinados valores, este texto busca identificar desenhos e delineamentos muito provisórios dos mapas que forjam a Amazônia que sofre de insônia, cujos olhos ardem com a fumaça espalhada pelo seu território e pelo sangue derramado em seus rios, em suas terras e florestas que pouco permite sonhar por estar desperta nas lutas que ocorrem em seu território.

Um segundo aspecto do artigo é o fato de que há um paradoxo na gestão da Amazônia, qual seja: o de governar um território para mantê-lo soberanamente nas condições de extração dos seus recursos ricos em biodiversidade, contudo, sem efetivamente propiciar um cuidado de fazer viver o povo dessa Região no que tange a garantia, promoção e defesa dos direitos da mesma. 
Para problematizar esse paradoxo, o texto está ancorado em contribuições de Michel Foucault, em especial, na apropriação do conceito de biopoder.

Esse artigo é fruto de um projeto de extensão e de pesquisa, na graduação e na pós-graduação, em Psicologia, articuladamente aos cursos de Direito, Serviço Social e de Pedagogia. Visa trazer análises das práticas desenvolvidas na formação de estudantes transdisciplinar pelo edital do Programa Institucional de Bolsas de Extensão Universitária (PIBEX), do Ministério da Educação, que ocorreu com movimentos sociais do Sudeste paraense e da Região do Tapajós, no Pará. Depois, se expandiu para a pesquisa documental e na pesquisaintervenção, em nível de Mestrado e de Doutorado, em Psicologia e no Direito, financiada pelo Conselho Nacional de Desenvolvimento Científico e Tecnológico (CNPq) e pela Coordenação de Aperfeiçoamento de Pessoal de Nível Superior (CAPES). A metodologia utilizada, nesse trabalho foi pautada na ferramenta genealógica, apropriada a partir de Foucault $(1979,1988)$, em que são analisadas relações de saber e de poder, dinâmicas, móveis e descontínuas, historicamente. Ainda, buscamos contribuições na cartografia em Deleuze $(1992,2005)$ e na análise institucional, em Lourau (1993).

\section{Direitos, economia política e gestão da vida na Amazônia Paraense}

Para Foucault (1999a; 2008a), a gestão do território em termos de confisco dos bens, das terras e dos corpos em formato de escravidão remete ao que ele designava de sociedades de soberania, em que governar o território e se apropriar de recursos e dos corpos era uma maneira de efetuar relações de poder específicas. Na Idade Média, essa modalidade de governo era recorrente e perdurou com certa expansão até, por volta do da segunda metade do século XVII, em muitos países.

Entretanto, a soberania de fazer morrer e deixar viver, bem como de confiscar bens e territórios ainda perdura, em alguns países, tendo mais expressão em uns e menos em outros. Todavia, a soberania foi atualizada e mesclada ao poder disciplinar e à biopolítica, no contemporâneo, configurando o biopoder, de acordo com Foucault (2008a).

Essa discussão é importante porque, em vários países o liberalismo, na segunda metade do século XVII emerge como gestão econômica e política da maneira de viver, de gerir recursos, de estabelecer leis para a realização do trabalho, de organizar relações sociais, de delimitar regras para a economia, enfim, trazendo um novo escopo de limites jurídicos para o poder soberano; agora, definido como Estado de Direito e não mais Monarquia Absolutista e, igualmente, criando leis para mediar relações sociais a partir da figura de sociedade como povo (FOUCAULT, 1988, 2008a).

Dessa forma, é formulado o contrato social por meio de outro tipo dessa nova soberania jurídica liberal, não mais pautada na figura do rei, monarca absolutista baseada no direito natural divino e também deslocando a noção de súditos servis ao rei para a de povo, sujeito de direitos. Essa transformação vem relacionada ao Iluminismo, às
Revoluções de Direitos (Francesa, Inglesa e Americana), à emergência da ciência, ao aparecimento do Estado de Direito e da sociedade. Simultaneamente, aparecem as cidades, a industrialização e as trocas mundiais pelo capitalismo mercantil e fisiocrata, na sequência.

A demanda por regulação do mercado internacional, do trabalho no contexto industrial e das relações entre Estado, sociedade e comércio na gestão do território, da saúde, da educação e da política social implica em uma série de mutações no âmbito do governo dos corpos. Uma nova racionalidade liberal da soberania jurídica do direito público, do direito trabalhista, do direito comercial e civil, juntamente com a difusão da produção da liberdade com segurança passa a ser vinculada ao estabelecimento de documentos de direitos humanos, de tratados e políticas para garantir o contrato social. Nesse aspecto, há um deslocamento e descontinuidade no objeto da soberania, segundo Foucault (1999a, 1999b, 2008a).

Obviamente, esse quadro europeu não o mesmo e nem ocorreu em uma mesma temporalidade na América, na África e na Ásia. Nos séculos XVII, XVIII, XIX e ainda, no XX, havia exploração colonial dos continentes: africano, americano e em parte do asiático pelos países europeus recentemente constituídos. Nesse ponto, há um paradoxo na soberania, pois, ao mesmo tempo em que a soberania do monarca entrava em mutação na Europa e se tornava Estado de Direito; nas colônias, havia ainda a soberania baseada no confisco, na pilhagem, no fazer morrer e deixar viver e na escravidão (SCHWARCZ, 1993; CARVALHO, 2009a, 2009b).

No Brasil, especificamente, apenas em 1822, a colônia se torna independente de Portugal com a emergência do Brasil Imperial, mas ainda regida pela transferência da Corte portuguesa. Essa mudança implicou no surgimento de várias instituições liberais ao longo da segunda metade do século XIX, em especial, a criação das Faculdades de Direito e de Medicina, a urbanização de várias cidades, o projeto de generalização da medicina social em campanhas de higiene e, em 1889, a proclamação da República. Em 1888, foi promulgada a Lei Áurea, abolindo a escravidão e, na sequência, são iniciadas as campanhas de imigração europeia e, posteriormente, a japonesa para o Brasil, deixando os povos negros, os caboclos e indígenas em situações precárias, vagando sem indenizações e alguma política social (FAUSTO, 2013).

A primeira República brasileira inicia um projeto modernizador liberal republicano, a partir de 1889. Emerge a figura do Estado brasileiro e da sociedade, em um contrato social, aparecer na relação com o sujeito de direitos, em um capitalismo extrativista, de industrialização incipiente e de uma economia de agronegócio. De 1930, em diante, ciclos de modernização e desenvolvimento nacionalista vão ganhando vulto e expressão. Apesar dessas transformações, há no Brasil, ainda marcas de pouco liberalismo político, econômico, de relações sociais, pessoais e de trabalho em vários lugares e mesmo nas capitais e estados considerados mais desenvolvidos na clave liberal (SCHWARCZ, 1993). 
Asmarcas evestígios do autoritarismo, do coronelismo, do clientelismo, do nepotismo e de trabalhos análogos ao escravo ainda estão presentes, sendo que, mais fortes em alguns estados e regiões do país e menos em outras. De todo modo, há atravessamento da soberania do fazer morrer e deixar viver ainda hoje, nas milícias, nos autos de resistência, no trabalho escravo moderno, na lógica do favor, no assistencialismo, no crime de pistolagem, na disputa de terras, na exploração de recursos naturais, na exploração sexual e tráfico humano, no agronegócio, no extrativismo predatório, na oligarquia rural, nos oligopólios midiáticos e em diversas posturas racistas e conservadoras (CARVALHO, 2001).

É possível afirmar que há no Brasil, durante o período republicano, várias iniciativas disciplinares e biopolíticas. Foucault (1999a) havia dito que, na Europa, a sociedade disciplinar geria os corpos individualmente e visa fazê-los aumentar a produtividade junto à docilidade política, desde o século XVII. Nessa forma de governo, o sujeito de direitos da soberania jurídica liberal convivia lado a lado com os corpos disciplinados pela educação, pela família, pelas fábricas, pelos hospitais e exércitos. No caso da biopolítica, na segunda metade do século XIX, além da disciplina individual, surge a gestão da população, por segmentos da sociedade, em nome da saúde e da vida, em que fazer viver e deixar morrer se torna mais importante do que fazer matar e deixar viver. Porém, esses mecanismos de poder e de saber não substituem o anterior da soberania do suplício dos corpos pelo soberano dos que considera seus servos. $\mathrm{O}$ que acontece e uma retração da soberania do suplício e uma reconfiguração da mesma na soberania jurídica, na disciplina e na biopolítica em termos de segurança, no que Foucault (2008a) nomeou como gestão do território e governo da população.

Esse é o paradoxo do biopoder, fazer viver e deixar morrer. Ou seja, no Estado Democrático de Direito, a autorização de deixar morrer e até mesmo de matar ocorre pela suspensão de direitos de alguns grupos sociais em nome da defesa da sociedade pelo racismo de Estado e de sociedade. Outro aspecto desse paradoxo é o dispositivo constitucional chamado de Estado de Exceção, em que as leis são violadas pelo Estado, justificadamente pela governabilidade e segurança da população. A racionalidade que sustenta essa perspectiva foi definida como biopolítica, para Foucault (1988, 1999b).

Bem, no Brasil, há poderes disciplinares, biopolíticos e do Estado Democrático de Direito, entretanto, após o fim da Ditadura Civil Militar, em 1985, com a promulgação da Constituição de 1988 e com uma série de parâmetros jurídicos democráticos. Mas prevalecem ainda projetos racistas, autoritários e escravocratas atualizados em vários lugares do Brasil e em muitas práticas, no presente.

Por exemplo, no caso da Amazônia paraense, há muitos resquícios do coronelismo, da oligarquia rural, do extrativismo, da apropriação de terras e dos recursos, de corpos pelo trabalho escravo e pelo tráfico de pessoas. A derrubada maciça da floresta e a venda ilegal de madeira para o exterior, a exploração sexual em rede de adolescentes da Ilha do Marajó e das áreas de garimpo do estado do Pará e seu envio para outros países por meio do tráfico de mulheres; a exploração de recursos energéticos por usinas, como: Tucuruí e, agora, com a construção de Belo Monte, a extração de minérios e a miséria e baixos impostos que deixam na região e o trabalho escravo em fazendas são exemplos concretos de poder soberano no Pará (MARTINS, 2009).

Resquícios das sociedades de soberania do fazer morrer e deixar viver existem, no Brasil e na Amazônia paraense. Um exemplo dessa situação é a morte frequente de lideranças de direitos humanos, constantemente ameaçadas e mortas por denunciarem as inúmeras e recorrentes violações de direitos no cotidiano da Amazônia. O extermínio de povos indígenas, de povos quilombolas, de ambientalistas, de lideranças da pastoral da terra e da pastoral da criança, lideranças de sindicatos rurais e de ativistas que criticam a política predatória realizada na região é algo que muito nos inquieta (CARVALHO, 2001; MELLO, 2006).

No caso da Amazônia, geograficamente delimitada como Região Norte brasileira e, posteriormente, chamada de Amazônia Legal, englobando alguns estados do Centro-Oeste e do Nordeste; há uma forma diferente de governo. Muitas tentativas de tomada desse território por espanhóis e holandeses ocorreu durante o período colonial e, a ideia de um lugar esvaziado, rico em recurso minerais e pela abundante fauna e flora trazia a visão de que o Brasil deveria ocupar para não entregar. Assim, as iniciativas, em especial, do Estado brasileiro foram de incentivar a ocupação por latifúndios; por projetos desenvolvimentistas verticais de criação de rodovias, de exploração de minérios e recursos naturais por indústrias de extração sem manufatura das riquezas extraídas e pela entrega sem impostos a empresas dos recursos citados como política de ocupação e gestão econômica desse território (GONÇALVES, 2010; FAUSTO, 2013).

$\mathrm{Na}$ Nova República, essa política teve poucas alterações, a Amazônia ainda é vista como um vazio populacional, terra de ninguém, lugar de disputas de terra e morte, o sangue é derramado na floresta sem muita intervenção do Estado, as empresas expropriam a região e deixam a miséria, os problemas ambientais e exploram uma mão de obra barata. Fazendeiros e empreiteiras usam trabalho análogo ao escravo, exploram sexualmente adolescentes e deixam poucos investimentos em termos de impostos e benfeitorias na região (LEONARDI, 1999; MELLO, 2006).

O desenvolvimentismo ainda vigora com a construção das hidrelétricas, de estradas, de portos e a vigilância do território ocorre pela militarização do mesmo para evitar revoltas face à realidade descrita. $\mathrm{O}$ exército e a Força Nacional são enviados à Amazônia para combater o contrabando de drogas e de armas e o tráfico humano pelos imensos rios e florestas, em fronteira com muitos países americanos e com a saída para o Oceano Atlântico pelo Pará. Também há uma pressão militar contra os movimentos sociais que lutam reivindicando políticas sociais e criticando essa relação 
do Estado brasileiro e das elites regionais e locais, em aliança para manutenção dessa configuração de forças exploratórias e de pilhagem de recursos e pessoas (AB'SÁBER, 2003; GONÇALVES, 2010).

Simultaneamente, na Amazônia, houve um período chamado áureo, o da Borracha entre o final do século XIX e as duas primeiras décadas do século XX. Nessa época, Belém e Manaus foram as capitais centrais na urbanização da Belle Epoché e das reformas higienistas, liberais e econômicas. Contudo, esse ciclo de riqueza e suposto desenvolvimento não foi expandido para toda a região nem para o interior do Amazonas e do Pará. As elites brancas regionais e locais se apropriaram do êxito provisório desse período durante a República Velha (DEAN; 1989; GONÇALVES, 2010).

Após o declínio da exportação da borracha, um longo tempo de miséria foi colocado no horizonte amazônico. Com o Golpe Militar e a Ditadura, a industrialização, o novo projeto de Segurança Nacional e o desenvolvimentismo nacionalista trouxe para a Amazônia uma segunda onda militarizada e de uma economia mineradora; do extrativismo da fauna, da flora e das águas pelas hidrelétricas. A entrega de terras para grandes empresas ocuparem o território gerou muitas disputas sangrentas com resquícios ainda presentes, na atualidade (DEAN, 1989; MELLO, 2006).

Assim, falamos de lutas não apenas no território por outras tensões, mas de intensa violência por terra e demarcação da mesma, pelo confisco de bens e dos corpos. Porém, também falamos de fazer viver e deixar morrer, de matar em nome da vida e em defesa da sociedade. É pensando nessas inquietações que nos ancoramos nas ideias desenvolvidas por Foucault (1999a, p. 13), principalmente em sua analítica do poder quando, ao fazer o uso da genealogia pretende propor que:

Intervenham saberes locais, descontínuos, desqualificados, não legitimados, contra a instância teórica unitária que pretendia filtrá-los, hierarquizá-los, ordená-los em nome de um conhecimento verdadeiro, em nome dos direitos de uma ciência que seria possuída por alguns. [...] Trata-se da insurreição dos saberes. Não tanto contra os conteúdos, os métodos ou os conceitos de uma ciência, mas de uma insurreição, sobretudo e acima de tudo contra os efeitos centralizadores de poder que são vinculados à instituição $\mathrm{e}$ ao funcionamento de um discurso científico organizado no interior de uma sociedade como a nossa.

A pertinência desta análise foucaultiana para se pensar o dispositivo amazônico reside no fato de que, por muito tempo este espaço vem sendo alvo de inúmeros olhares e interesses de organizações governamentais, empresas privadas, "homens da ciência", que com o discurso de buscar obter um maior conhecimento sobre a região e de proporcionar maior segurança e desenvolvimento, mobilizaram práticas de violência, de submissão. Essas práticas ocorreram em acordo com muitos grupos de interesse que desejavam se apropriar

Fractal, Rev. Psicol., v. 28 - n. 3, p. 316-323, 2016 dos recursos da biodiversidade da região e sujeitavam os povos locais aos regimes de verdade dominação da região amazônica (MELLO, 2006).

Tendo este quadro em vista, são as relações e práticas de poder que vêm sendo tecidas na Amazônia e que geram efeitos singulares que desejamos interrogar bem como os resquícios da escravidão, do coronelismo oligarca do controle das terras e de extração dos recursos da floresta. Esse objeto aparece como efeito de racionalidades ecológicas e desenvolvimentistas, econômicas e modernizantes, articuladamente às práticas anteriores ao liberalismo e simultaneamente às de um liberalismo republicano autoritário e exploratório. Assim, foi materializado um paradoxo de apropriação das riquezas, em meio ao surgimento das luzes dos direitos e da modernização econômica e política. Concomitantemente, o suplício soberano da dominação carismática, patriarcal, populista e dominadora ainda subsiste, na região em meio à violência, ao confisco de terras, de corpos e de recursos naturais.

\section{Amazônia: espaço de lutas de saber e poder}

A Amazônia na sua atual conjuntura, como um território permeado de lutas e embates políticos é produto de inúmeros fatores históricos, políticos, sociais e econômicos, dentre estes, merece destaque a compreensão que esse território teve durante a história brasileira de uma região rica em recursos naturais, e que por isso devia ser alvo de uma política que visasse a sua suposta integração à noção de nação que se desenvolvia e buscava ampliar seu território e domínio econômico. Becker (2005) fez uma análise sobre essa geopolítica, na Amazônia como estratégia de controle do território, traçando uma mudança da própria geopolítica que, historicamente se caracterizava pela pressão de todos os tipos sobre os Estados, através de intervenções variadas para a conquista de territórios e colônias, em uma geopolítica que hoje, atua, acima de tudo, por meio de estratégias de dominação e violência.

De acordo com Foucault (1995), há uma diferença conceitual no que ele chama de governamentalidade da soberania jurídica, de governo disciplinar, de violência e das relações de poder e saber. $\mathrm{Na}$ dominação, há estigma e preconceito de gênero, raça, classe, religião secular com tendência cultural mais cristalizada e difícil de romper; na violência, praticamente não como resistir, pois, acorrentado e com uma arma apontada para a cabeça é difícil produzir liberdade; já, a disciplina e a biopolítica são mais modulares, deslizam entre a norma e a lei, focando o indivíduo e a população em termos de saber e poder. Assim, poder é uma relação, uma força com força, ação sobre ação que permite resistências e só pode existir pela construção da liberdade.

Bem, é possível afirmar que essas várias modalidades de poder se concretizam, na Amazônia, na gestão dos indivíduos e no governo das condutas da população. No caso da soberania jurídica, tenta-se criar políticas de defesa e garantia de direitos, na região e no aspecto da violência e do suplício ainda impera a dominação 
e a soberania patriarcal, do coronel, do pistoleiro e do oligarca que manda matar, que comete chacinas em conjunto com milícias etc.

Esses acontecimentos estão ligados à história do Brasil e da Amazônia. A ocupação e o povoamento deste território pelos portugueses, nos tempos coloniais, não se deu de forma intensiva, visto a dificuldade de povoar este espaço de grandes rios e mata fechada. Assim, a manutenção e a expansão desse território para além dos limites impostos previstos pelo Tratado de Tordesilhas, foram conseguidas por Portugal graças a uma estratégia geopolítica, ou seja, de controle do território (BECKER, 2005).

Nas primeiras décadas do século XX, no governo de Getúlio Vargas, de uma forma mais contínua, diferentemente do que tinha ocorrido nos períodos do Brasil Colônia e Império. Este projeto se ampliou no período da Ditadura Militar onde se colocou em prática um amplo Programa de ocupação econômica da Amazônia brasileira, assentada em bases supostamente modernas. Com o lema "integrar para não entregar" os militares continuavam os objetivos geopolíticos falando em "ocupação dos espaços vazios", apesar da ocupação da região por inúmeras tribos indígenas e populações camponesas que já se encontravam na região desde o século XVIII (MARTINS, 2009).

Essas políticas de integração da Amazônia geraram como resultado a execução de grandes projetos de infraestrutura física, como as grandes rodovias e as construções de hidrelétricas. Esses projetos colocaram a Amazônia numa nova divisão internacional do trabalho, no qual o Brasil entra com um grande mercado interno, uma enorme disponibilidade de recursos naturais, um baixo custo de mão de obra, e fabricante de produtos intensivos em energia e altamente poluidores. Com isso, a região amazônica sofre com o aproveitamento de seus recursos naturais por meio dos grandes projetos, numa lógica totalmente inadequada para as condições regionais, expressandose nos impactos ambientais e socioeconômicos negativos (CENTRO DE ESTUDOS E DEFESA DO NEGRO NO ESTADO DO PARÁ [CEDENPA], 2008).

Esses grandes projetos que foram executados e os que estão em andamento ou que ainda irão se implantar na Amazônia, possuem algumas características comuns e apresentam alguns elementos básicos. A verticalização é o primeiro deles, pois esses projetos continuam a ser concebidos para interesses externos à região, ignorando muitas vezes os interesses dos movimentos sociais da região, porém, podendo ter alianças com setores ruralistas e ligados às mineradoras do Pará (GONÇALVES, 2010).

A fragmentação é outra dessas características, pois esses projetos não apresentam uma visão abrangente das implicações que produzem ao ambiente e às populações amazônicas. Uma terceira característica é a grande ausência de políticas públicas adequadas às especificidades da realidade regional. E por último, temos a violência como base constitutiva da expansão do capital na região (CEDENPA, 2008). Todas essas características são atravessadas por elementos de dominação, de segregação, mas igualmente do que Foucault $(1988,1999 b)$ denominou de um racismo de Estado e de sociedade.

Esse conceito expressa bem muitas políticas que são estabelecidas para a região amazônica, ou seja, políticas racistas e de extermínio. O racismo de Estado e de sociedade é um conceito desenvolvido por Foucault que pode ser mais bem entendido se seguirmos o percurso da trajetória de seu pensamento. Foucault inicia a sua análise a partir da apreciação de como a soberania, no sentido político clássico, se apossou sobre o poder de vida e de morte sobre seus súditos, ou seja, como o soberano com o direito de matar exerceu um direito sobre a vida de seus súditos e "é essencialmente um direito de espada. [...] É o direito de fazer morrer ou de deixar viver" (FOUCAULT, 1999b, p. 287).

Em seguida, Foucault já nos fala de uma transformação nesse direito político da soberania que vai gerar um novo direito, um direito "que não vai apagar o primeiro, mas vai penetrá-lo, perpassá-lo, modificá-lo, e que vai ser um direito, ou melhor, um poder exatamente inverso: poder de 'fazer' viver e de 'deixar' morrer" (FOUCAULT, 1999 b, p. 287). Essa inversão viria desde o nascimento do contrato social quando os súditos delegavam ao soberano jurídico poder sobre sua própria vida, já que o contrato residia justamente numa expectativa de proteção sobre a vida, constituindo assim, um novo direito para o soberano, um direito sobre a vida (FOUCAULT, 1988).

A seguir, sua análise sobre este novo direito político Foucault abdica de uma análise a partir da teoria política, mas sim, como é de praxe na sua genealogia, no nível dos mecanismos, das técnicas, das tecnologias de poder. Uma primeira tecnologia que aparece é aquela que se centra no corpo do indivíduo cujos procedimentos visavam assegurar sua distribuição espacial, aumentarlhes a força útil, tendo em vista tornar esses corpos úteis economicamente e dóceis politicamente, esta tecnologia foi chamada por Foucault $(1979,1999 a)$ de uma tecnologia disciplinar.

A segunda tecnologia que vai surgir na segunda metade do séc. XVIII está, segundo Foucault, em outro nível da tecnologia disciplinar e que por isso não suprime esta. Este outro nível não se refere mais ao corpo, ou homem-corpo, mas ao homem vivo, ao homem-espécie, aos próprios processos da vida, e por isso vai ser chamada de biopolítica, diferente da tecnologia disciplinar que pode ser vista como uma anátomo-política, já que atua no nível do corpo (FOUCAULT, 1999b).

Essa anátomo-política que compõe a disciplina vai se ocupar da "multiplicidade dos homens na medida em que essa multiplicidade pode e deve redundar em corpos individuais que devem ser vigiados, treinados, utilizados, eventualmente punidos" (FOUCAULT, 1999b, p. 289).

A biopolítica atua também sobre a multiplicidade dos homens, mas atem-se naquilo que a multiplicidade forma, ao contrário de corpos, "uma massa global, afetada por processos de conjunto que são próprios da 
vida, que são processos como o nascimento, a morte, a produção, a doença etc.”. Assim, essa biopolítica vai ter como seus primeiros alvos de controle, primeiros objetos de saber: os processos de natalidade, de mortalidade, de longevidade, os problemas econômicos e políticos, e para isso vai lançar mão da medição estatística, das primeiras demografias (FOUCAULT, 2008a).

Esses procedimentos aplicados à população vão permitir uma maior quantificação dos principais processos da vida e regular estes processos a partir de três domínios principais: a questão da natalidade, da mortalidade e da longevidade, onde a biopolítica atua para fazer a vida se estender ao máximo, utilizando-se da medicina para exercer a higiene pública, com campanhas de higiene e medicalização da população; a questão da velhice, dos acidentes e das doenças, que vai fazer surgir às instituições de assistência, de poupança, de seguridade; e por último, a questão do meio geográfico, ou seja, do espaço, onde a preocupação com a organização da cidade vai surgir (FOUCAULT, 1999b).

É no encontro entre as duas principais tecnologias de poder em meio ao Estado liberal, o disciplinar e o regulamentar, o que se aplica ao corpo e aquele que se aplica à população, a anátomo-política e a biopolítica, é neste encontro que vai ser possível emergir a sociedade da normalizadora (EWALD, 1993). A norma como aquela que se aplica tanto a um corpo que se disciplina como a uma população que se regulamenta. Assim, a sociedade de normalização se caracteriza por ser um poder que:

Tomou posse da vida, [...] incumbiu-se da vida, [...] conseguiu cobrir toda a superfície que se estende do orgânico ao biológico, do corpo à população, mediante o jogo duplo das tecnologias de disciplina, de uma parte, e das tecnologias de regulamentação, de outra (FOUCAULT, 1999a, p. 302).

É por meio dessas relações de poder que tem como objeto e objetivo a vida que Foucault vai se perguntar como um:

Poder como este pode matar, se é verdade que se trata essencialmente de aumentar a vida, de prolongar sua duração, de multiplicar suas possibilidades, de desviar seus acidentes, ou então de compensar suas deficiências? Como, nessas condições, é possível, para um poder político, matar, reclamar a morte, pedir a morte, mandar matar, dar a ordem de matar, expor à morte não só seus inimigos, mas mesmo seus próprios cidadãos? Como esse poder que tem essencialmente o objetivo de fazer viver pode deixar morrer? Como exercer o poder da morte, como exercer a função da morte, num sistema político centrado no biopoder? (FOUCAULT, 1999a, p. 304).

É para dar respostas a essas indagações, que Foucault vai se referir ao racismo, que passa a se inserir nos mecanismos do Estado a partir da emergência do biopoder. Mas, afinal, como esse racismo vai compor essas novas tecnologias de poder e fazer com que os mecanismos fundamentais do poder dos Estados modernos passem fundamentalmente pelo racismo?
Isso deve ser respondido através de outra pergunta fundamental: o que é o racismo dentro desse biopoder? E Foucault nos dirá que é

O meio de introduzir afinal, nesse domínio da vida de que o poder se incumbiu um corte: o corte entre o que deve viver e o que deve morrer. No contínuo biológico da espécie humana, o aparecimento das raças, a distinção das raças, a hierarquia das raças, a qualificação de certas raças como boas e de outras, ao contrário, como inferiores, tudo isso vai ser uma maneira de fragmentar esse campo do biológico de que o poder se incumbiu; uma maneira de defasar, no interior da população, uns grupos em relação aos outros. [...] Essa é a primeira função do racismo: fragmentar, fazer cesuras no interior desse contínuo biológico a que se dirige o biopoder (Foucault, 1999a, p. 304).

É sobre essa lógica, infelizmente, que podemos pensar as práticas estatais voltadas à Amazônia, a fronteira brasileira por excelência. Fronteira, que no Brasil, significa frequentemente o limite do próprio humano (MARTINS, 2009). É sobre essa concepção de fronteira que podemos ver atravessada uma segunda função do racismo dentro do biopoder, uma função que, segundo Foucault, é a de uma relação positiva do tipo quanto mais você matar, mais você fará morrer, ou quanto mais você deixar morrer, mas; por isso mesmo, você viverá. É a relação guerreira: para viver, é preciso que você massacre os seus supostos inimigos.

Ora, é o racismo que faz justamente funcionar, faz atuar essa relação do tipo guerreiro - se você quer viver, é preciso que o outro morra - de uma maneira que é inteiramente nova e que, precisamente, é compatível com o exercício do biopoder (FOUCAULT, 1999b, p. 305).

É essa lógica que vem perpetuando as chamadas frentes pioneiras e frentes de expansão que avançam em direção a Amazônia, aquela que parece ser a última grande fronteira a ser explorada. Essas "frentes", que apesar de serem duas designações diferentes falam da mesma coisa, ou seja, dos diferentes modos como os que se nomeiam como "civilizados" se expandem territorialmente e utilizam lugares institucionais, muitas vezes, estatais e de proteção para violar direitos e sustentar relações de cumplicidade com as violações vigentes, no Pará (MELLO, 2006; MARTINS, 2009).

Se por um lado a frente pioneira traz uma ideia de que se está levando para a fronteira o novo, o moderno, melhores concepções de vida e uma grande mudança social, contrapondo-se às regiões antigas às quais essas frentes pretendiam conquistar e, que se caracterizavam por um suposto vazio da população vista como: rotineira, tradicionalista e, portanto, muitas vezes, morta e desqualificada (GONÇALVES, 2010).

Por outro lado, a frente de expansão designa tanto uma expansão da própria sociedade nacional como do próprio capitalismo e seu modo de produção, fazendo com que esse termo adquira um viés econômico. Contudo, essas definições marcam o próprio "lugar" da fronteira, que é o lugar do conflito (MARTINS, 2009). Tensão que tem levado a inúmeras violações aos direitos fundamentais 
das populações amazônicas e um caso singular que reflete todo o processo de violação são o dos chamados Defensores de Direitos Humanos (DDH's). Esses DDH's atuam na promoção e proteção dos direitos humanos e as liberdades fundamentais reconhecidas ou mesmo na denúncia de violações a esses direitos.

Os DDH's dentro do território amazônico são representados principalmente por sindicalistas e integrantes de organizações não governamentais (ONGs), religiosos, líderes comunitários, lideranças de trabalhadores rurais sem terra, líderes quilombolas e indígenas, agentes públicos, advogados, ambientalistas, entre outros que trabalham e atuam na promoção e proteção dos direitos humanos. Ao se incumbirem dessa tarefa de trabalhar na linha de frente desses conflitos esses DDH's são expostos a uma série de violações, sendo ameaçados de morte e, chegando a serem mortos.

A primeira dessas violações é o chamado processo de difamação ou demonização dos DDH's que consiste em um ataque à imagem e idoneidade dos defensores à comunidade e à opinião pública. A segunda forma seria a criminalização dos DDH's e dos movimentos sociais e consiste em ações que pode se dar de forma isolada ou em conjunto com as outras formas de violação por meio de prisões, inquéritos, Termos Circunstanciados de Ocorrência (TCO's), procedimentos judiciais cíveis e criminais abertos contra esses defensores como retaliação às suas atividades.

A última dessas violações consiste na vitimização dos DDH's e configuram-se em ameaças, violências e outros crimes que são feitos para impedir que o defensor ou uma determinada organização continue com sua atuação, ou mesmo com retaliação ou vingança (CEDENPA, 2008). Estes processos são vistos em inúmeros casos como Dom Erwin Krautler (bispo do Xingu), José Brito (sindicalista do município de Abel Figueiredo), Maria Joel (sindicalista de Rondon do Pará), Maria Ivete Bastos dos Santos (sindicalista do município de Santarém), Raimundo Nonato - Italiano - (liderança de trabalhadores rurais do acampamento Carajás em Parauapebas), além de casos contra movimentos sociais como o Movimento dos Sem Terra (MST), o Movimento de Atingidos por Barragem (MAB) e Entidades Não Governamentais como o Greenpeace (MELLO, 2006; GONÇALVES, 2010).

$\mathrm{O}$ caso mais emblemático e conhecido que foi o da missionária americana Dorothy Stang que foi declarada persona non grata pela Câmara Municipal de Altamira, foi indiciada num inquérito policial, sofreu um processo criminal, foi ameaçada e ao resistir a todos essas tentativas de intimidação dos seus inimigos foi assassinada (CEDENPA, 2008). Esses e outros casos são exemplos verídicos dessa realidade conflitiva que marca a fronteira amazônica e do racismo de Estado que atravessa esta. Dominação étnica, racial, de classe, de gênero e social que coloca a fronteira como o lugar da alteridade e mesmo da impossibilidade de existência.

\section{Biopoder na Amazônia no fazer viver, deixar morrer e matar em nome da vida: de quem?}

No entanto, apesar dessas políticas de biopoder, e de, junto com ele, um racismo de estado nas políticas públicas voltadas para a Amazônia, pode-se encontrar várias resistências nessa rede de relações de poder. Como fora dito anteriormente, essa geopolítica contemporânea ao mesmo tempo em que possibilitou a formação de dominações desenvolvidas em redes para a seleção de territórios, de acordo com suas possibilidades, permitiu de igual modo, a criação de vários movimentos sociais transnacionais. Hoje, com as mudanças efetuadas no capitalismo e no sistema internacional, quem passou a ocupar o espaço que outrora pertencia aos partidos políticos na incumbência de criarem difusões de justiça social, foi o discurso dos direitos humanos, que fez com que o papel de catalisadores da ação coletiva passasse dos partidos políticos para as ONGs e de Movimentos Sociais (SORJ, 2004). Essa realidade das entidades civis pode ser pensada a partir da lógica proposta por Foucault onde destaca que a política (poder) é a continuidade da guerra por outros meios e consiste numa nova analítica do poder em que:

As relações de poder, tais como funcionam numa sociedade como a nossa, têm essencialmente como ponto de ancoragem uma certa relação de força estabelecida em dado momento, historicamente precisável, na guerra e pela guerra. [...] O poder político, nessa hipótese, teria como função reinserir perpetuamente essa relação de força, mediante uma espécie de guerra silenciosa, e de reinseri-la nas instituições, nas desigualdades econômicas, na linguagem, até nos corpos de uns e de outros (FOUCAULT, 1999b, p. 22).

Esse poder, do qual Foucault $(1979,1988)$ nos fala, apenas pode ser pensado e analisado no campo de batalha, nos espaços em que as lutas são travadas e onde se podem ver os efeitos resultantes dessas lutas. No caso da Amazônia, esse ringue é claramente visualizado nos intensos debates, protestos, promovidos pelos movimentos sociais, ONG's, e outros agrupamentos que formam esse importante ator da atual configuração política brasileira que é a sociedade civil organizada, forjando assim espaços de resistências frente às forças políticas e econômicas dominantes. As práticas e tecnologias de poder exercidas por esses polos de concentração de poder político e econômico (madeireiros, sojeiros, grileiros, pecuaristas, empresas de mineração) são de dominação e sujeição em relação aos que se encontram nos focos de resistência das práticas exercidas por aqueles que se utilizam da violência para promover seus interesses. Como bem nos expõe Martins (2009, p. 133), embasado em sua rica pesquisa de trinta anos nas frentes de expansão da Amazônia Legal, que entre 1968 e 1987:

Diferentes tribos indígenas da Amazônia sofreram pelo menos 92 ataques organizados, principalmente por grandes proprietários de terra, com a participação de seus pistoleiros, usando armas de fogo. Por seu lado, diferentes tribos indígenas realizaram pelo menos 165 ataques a grandes fazendas e a alguns povoados, entre 1968 e 1990, usando muitas vezes armas primitivas como borduna, arco e flecha. 
Entre os diferentes confrontos travados, por diversas práticas sociais do espaço amazônico como indígenas, comunidades ribeirinhas e povos quilombolas foi possível ver que esta constatação também tem suas maneiras de operar. Apenas a partir desses confrontos travados é que foi possível descrever e analisar estas práticas sociais para afirmar alguns dos direitos humanos (consagrados pelas grandes cartas e tratados internacionais que insistem em proteger apenas o lado de cá da fronteira, já que esta é o lado dos supostos e únicos "humanos") para os seus coletivos e suas causas.

Sabe-se que a mídia, na maioria das vezes, produz uma visão que colabora para a violação de direitos e para a criminalização dos movimentos sociais perante a sociedade, fortalecendo uma imagem negativa destes, ajudando assim, a corroborar as práticas de violação que promovem a difamação e demonização desses movimentos, relacionando-os aos "defensores de bandido, invasores de terra e causadores de confusão". Apesar disso, é cada vez mais forte a atuação dessas entidades civis e seus representantes, principalmente quando essas várias entidades estabelecem relações com o intuito de formar uma Rede Solidária (CEDENPA, 2008).

Esta rede busca fortalecer a atuação daqueles líderes que têm sido ameaçados, que lutam sem proteção efetiva, com os direitos violados, inclusive pelos que deveriam cuidar da vida destes grupos no campo das instâncias jurídicas e das políticas públicas; de forma que analisamos, neste texto, um cenário de morte anunciada cotidianamente na Amazônia da música de Roberto Carlos, que tem vivido de certa maneira a "insônia do mundo".

Assim, se há tecnologias de poder e situações de violência, há também estratégias de resistência de diferentes grupos sociais e no corpo a corpo permanente de busca pela criação de outras fotografias da Amazônia e de outras relações de força que operem práticas de lutas contra a exploração, o tráfico de pessoas, a escravidão, o confisco de terras arbitrário e contra as mortes dos ativistas que fazem estas batalhas.

A produção da resistência é uma prática contínua e viva na região paraense, desde o Movimento da Cabanagem, aliás, desde a resistência indígena à colonização e à tentativa de escravizar os povos indígenas ela ocorre no Estado até à atualidade, em que militantes são mortos e ameaçados justamente porque lutam e reivindicam condições outras de existência que sejam afirmativas de direitos e, ao mesmo tempo, disruptivas com as desigualdades e explorações em jogo, neste território brasileiro.

\section{Referências}

AB'SÁBER, A. Os domínios de Natureza no Brasil: potencialidades paisagísticas. São Paulo: Ateliê, 2003.

BECKER, B. K. Geopolítica da Amazônia. Estud. Av., [S.1.], v. 19, n. 53, p. 71-86, 2005.

CARVALHO, J. M. Cidadania no Brasil: um longo caminho. Rio de Janeiro: Civilização Brasileira, 2001.

CARVALHO, J. M. Os bestializados: o Rio de Janeiro e a República que não foi. São Paulo: Companhia das Letras, 2009a.
CARVALHO, J. M. A formação das almas: o imaginário da República no Brasil. São Paulo: Companhia das Letras, 2009b.

CENTRO DE ESTUDOS E DEFESA DO NEGRO NO ESTADO DO PARÁ (Org.). Em defesa da vida: a realidade dos/as defensores/as de direitos humanos sob situação de risco e ameaça no Estado do Pará. Belém: CEDENPA, 2008.

DEAN, W. A luta pela borracha no Brasil: um estudo de história ecológica. São Paulo: Nobel, 1989.

DELEUZE, G. Conversações. Rio de Janeiro: Editora 34, 1992.

DELEUZE, G. Foucault. São Paulo: Brasiliense, 2005.

EWALD, F. Foucault, a norma e o direito. Lisboa: Vega, 1993.

FAUSTO, B. História do Brasil. São Paulo: EdUSP, 2013.

FOUCAULT, M. Microfisica do poder. Rio de Janeiro: Graal, 1979.

FOUCAULT, M. História da Sexualidade: a vontade de saber. Rio de Janeiro: Graal, 1988. v. 1.

FOUCAULT, M. O sujeito e o poder. In: DREYFUS, H.; RANINOW, P. Michel Foucault: uma trajetória filosófica. Para além do estruturalismo e da hermenêutica. Rio de Janeiro: Forense, 1995. p. 173-295.

FOUCAULT, M. Em defesa da Sociedade: Curso no Collége de France (1975-1976). 3. ed. São Paulo: Martins Fontes, 1999a.

FOUCAULT, M. Vigiar e Punir: a história da violência nas prisões. São Paulo: Martins Fontes, 1999b.

FOUCAULT, M. Segurança, território e população. São Paulo: Martins Fontes, 2008a.

GONÇALVES, C. W. P. Amazônia, Amazônias. São Paulo: Contexto, 2010

LEONARDI, V. Os historiadores e os rios: natureza e ruína na Amazônia brasileira. Brasília: EdUNB, 1999.

LOURAU, R. Renè Lourau na UERJ 1993: Análise Institucional e práticas de pesquisa. Rio de Janeiro: EdUerj, 1993.

MARTINS, J. de S. Fronteira: a degradação do Outro nos confins do humano. São Paulo: Contexto, 2009.

MELLO, N. A. Políticas territoriais na Amazônia. São Paulo: Annablume, 2006.

ROBERTO CARLOS; ERASMO CARLOS. Amazônia. Intérprete: Roberto Carlos. In: ROBERTO CARLOS Amazônia. [S.1.]: CBS, 1989. 1 disco sonoro. Lado A, faixa 1.

SCHWARCZ, L. M. O espetáculo das raças: cientistas, instituições e questão racial no Brasil, 1870-1930. São Paulo: Companhia das Letras, 1993.

SORJ, B. A democracia inesperada: cidadania, direitos humanos e desigualdade social. Rio de Janeiro: J. Zahar, 2004.

Recebido em: 10 de outubro de 2012

Aceito em: 22 de abril de 2015 